\title{
Surgery for \\ Congenital Heart \\ Disease
}

\section{Inclusion of oxygen consumption improves the accuracy of arterial and venous oxygen saturation interpretation after the Norwood procedure}

Jia Li, MD, PhD, Gencheng Zhang, MD, PhD, Helen M. Holtby, MBBS, Brian W. McCrindle, MD, MPH, Sally Cai, PhD, Tilman Humpl, MD, Christopher A. Caldarone, MD, William G. Williams, MD, Andrew N. Redington, MD, and Glen S. Van Arsdell, MD

From the Cardiac Program, the Hospital for Sick Children, Toronto, Ontario, Canada.

Read at the Eighty-fifth Annual Meeting of The American Association of Thoracic Surgery, San Francisco, Calif, April 10-13, 2005.

Received for publication April 8, 2005; revisions received Oct 5, 2005; accepted for publication Oct 10, 2005

Address for reprints: Glen S. Van Arsdell, MD, Division of Cardiovascular Surgery, The Hospital for Sick Children, 555 University Ave, Toronto, Ontario, Canada M5G 1X8 (E-mail: glen.vanarsdell@ sickkids.ca).

J Thorac Cardiovasc Surg 2006;131:1099-107 0022-5223/ $\$ 32.00$

Copyright $\odot 2006$ by The American Association for Thoracic Surgery

doi:10.1016/j.jtcvs.2005.10.057
Objective: Management strategy for the postoperative Norwood neonate has been formulated from models that have estimated oxygen consumption $\left(\mathrm{VO}_{2}\right)$. Superior vena caval oxygen saturation $\left(\mathrm{SvO}_{2}\right)$, systemic arterial and superior vena caval oxygen saturation difference $\left(\mathrm{Sa}_{-} \mathrm{VO}_{2}\right)$, and oxygen excess factor $(\Omega=$ arterial oxygen saturation $\left./ \mathrm{Sa}-\mathrm{VO}_{2}\right)$ have been used as indirect indicators to estimate systemic blood flow $(\mathrm{Qs})$ and oxygen delivery $\left(\mathrm{Do}_{2}\right)$. We sought to examine the correlation of the indirect indicators to $\mathrm{VO}_{2}$-derived measures of oxygen transport.

Methods: Respiratory mass spectrometry was used to continuously measure $\mathrm{vo}_{2}$ after the Norwood procedure $(n=13)$. Measured saturations and the direct Fick equation were used to obtain pulmonary blood flow, $\mathrm{Qs}, \mathrm{DO}_{2}$, and oxygen extraction ratio $\left(\mathrm{ERO}_{2}\right)$ values. Correlations to $\mathrm{SvO}_{2}, \mathrm{Sa}_{-} \mathrm{VO}_{2}$, and $\Omega$ were sought.

Results: There was a close correlation of $\mathrm{SvO}_{2}, \mathrm{Sa}_{-} \mathrm{vO}_{2}$, and $\Omega$ to $\mathrm{ERo}_{2}(r=0.92$, 0.96 , and 0.97 , respectively; $P<.0001$ ). Correlation to $\mathrm{Qs}_{\text {s }}$ and $\mathrm{Do}_{2}$ was variable $(r=0.39$ to 0.78 , respectively; $P<.0001)$. Correlation to $\mathrm{vo}_{2}$ was poor but significant $\left(r=0.24\right.$ to $0.40, P<.0001$ ). Inclusion of $\mathrm{vO}_{2}$ improved the correlation to Qs and $\mathrm{Do}_{2}(r=0.66$ to $0.97, P<.0001)$.

Conclusions: The close correlation of $\mathrm{SvO}_{2}, \mathrm{Sa}_{-} \mathrm{vO}_{2}$, and $\Omega$ to $\mathrm{ERO}_{2}$ indicates that each is a measure of the balance of $\mathrm{Do}_{2}$ and extraction. The significant but less reliable correlation to $\mathrm{Do}_{2}$ and $\mathrm{vo}_{2}$ indicates the values for $\mathrm{SvO}_{2}, \mathrm{Sa}^{-\mathrm{vO}_{2}}$, and $\Omega$ do not discriminate between the contribution of $\mathrm{DO}_{2}$ and $\mathrm{vO}_{2}$. Measured $\mathrm{vO}_{2}$ and hemodynamics may improve the optimization of postoperative management strategy in the individual neonate.

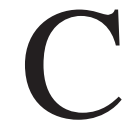
are of the postoperative Norwood patient continues to be challenging. ${ }^{1-6}$ Performance requirements for the single ventricle with a parallel circulation are substantial and are made more physiologically stressful by the recent insult of cardiopulmonary bypass (CPB) and myocardial ischemia. Postoperative management strategies are predicated on balancing pulmonary (Qp) and systemic (Qs) blood flow ${ }^{6-8}$ and optimizing systemic oxygen delivery $\left(\mathrm{Do}_{2}\right){ }^{9-12}$ These strategies have been designed on the basis of experimental models, ${ }^{13}, 14$ theoretic models, ${ }^{15-17}$ and human studies ${ }^{3,5,11,18}$ that have intrinsic limitations. Experimental 

Abbreviations and Acronyms
$\mathrm{Do}_{2} \quad=$ oxygen delivery
$\mathrm{ERO}_{2}=$ oxygen extraction ratio
$\Omega \quad=$ oxygen excess factor
$\mathrm{Qp} \quad=$ pulmonary blood flow
Qs = systemic blood flow
$\mathrm{SaO}_{2}=$ arterial oxygen saturation
$\mathrm{Sa}-\mathrm{VO}_{2}=$ systemic arterial and venous oxygen saturation difference
$\mathrm{SvO}_{2}=$ systemic venous oxygen saturation
$\mathrm{VO}_{2}=$ oxygen consumption

animal models might not fully reflect human physiology. Mathematic models require assumptions that might differ from those seen clinically. To date, human models have used estimations of, rather than directly measured, oxygen consumption $\left(\mathrm{VO}_{2}\right)$ and pulmonary venous saturations. ${ }^{3,5,11,18}$

Because of the difficulties in obtaining measured Qs, $\mathrm{Do}_{2}$, and $\mathrm{Qp}$ values, decision making for postoperative management is based on reflectors of $\mathrm{Do}_{2}$ and $\mathrm{Qs}$, as well as an estimated pulmonary venous oxygen saturation. The reflectors of $\mathrm{Do}_{2}$ and $\mathrm{Qs}$ are superior vena caval oxygen saturation $\left(\mathrm{SvO}_{2}\right),{ }^{5,8,19}$ the difference between arterial and venous oxygen saturations $\left(\mathrm{Sa}-\mathrm{VO}_{2}\right)$ and oxygen excess factor $(\Omega=$ arterial oxygen saturation $\left.\left[\mathrm{SaO}_{2}\right] / \mathrm{Sa}-\mathrm{VO}_{2}\right){ }^{3-7,11,12,18}$

$\mathrm{Qp}$ is generally accounted for by making an estimation that pulmonary venous saturation is greater than $95 \% .^{3,5,11,18,19}$ This estimation is not always correct. ${ }^{8}$
The above-outlined parameters can be obtained with minimal difficulty in clinical practice but have the limitation of not accounting for interindividual and intraindividual variability of $\mathrm{VO}_{2} \cdot{ }^{20-24}$ It has been increasingly realized that changes in $\mathrm{VO}_{2}$ might have an important effect on hemodynamics and oxygen transport. ${ }^{20-24}$ Changes in $\mathrm{VO}_{2}$ might not be fully reflected or understood for the commonly measured values $\mathrm{SvO}_{2}, \mathrm{Sa}_{\mathrm{VO}}$, and $\Omega$. We sought to examine the correlation of $\mathrm{SvO}_{2}, \mathrm{Sa}_{-} \mathrm{VO}_{2}$, and $\Omega$ to hemodynamics and oxygen transport parameters obtained by using $\mathrm{VO}_{2}$ and the direct Fick equation.

\section{Materials and Methods \\ Patients}

This study was approved by the Research Ethics Board at the Hospital for Sick Children, Toronto, Canada. Written informed consent was obtained from the parents of 13 of the 16 infants (12 boys; age range, 4-92 days; median, 7 days) undergoing a Norwood procedure between April and October 2004. The patient demographics are shown in Table 1. Three patients were not recruited for the study because of nonclinical issues.

\section{Intraoperative Procedures}

All patients were intubated with cuffed endotracheal tubes (Mallinckrodt Medical, Northampton, United Kingdom). General anesthesia was maintained with inhaled isoflurane, intravenous fentanyl, and pancuronium bromide. Low-flow CPB and selective cerebral perfusion were used in 12 of 13 patients. A standard Norwood procedure was used. ${ }^{25}$ The aortic arch was reconstructed with a homograft patch. The 3.5-mm right modified BlalockTaussig shunt was completed with anastomosis of the distal conduit to the central pulmonary artery. All patients received methylprednisolone $(30 \mathrm{mg} / \mathrm{kg})$ in the operating room at or before CPB. Phenoxybenzamine, $0.25 \mathrm{mg} / \mathrm{kg}$, was administered

TABLE 1. Clinical data for the 13 patients

\begin{tabular}{|c|c|c|c|c|c|c|c|c|}
\hline Patient & $\begin{array}{l}\text { Age } \\
\text { (d) }\end{array}$ & $\begin{array}{l}\text { Weight } \\
\text { (kg) }\end{array}$ & $\begin{array}{l}\text { BSA } \\
\left(\mathrm{m}^{2}\right)\end{array}$ & $\begin{array}{l}\text { CPB } \\
(\min )\end{array}$ & $\begin{array}{l}\text { ACC } \\
(\mathrm{min})\end{array}$ & $\begin{array}{l}\text { Circulatory } \\
\text { arrest (min) }\end{array}$ & $\begin{array}{c}\text { Cerebral } \\
\text { perfusion (min) }\end{array}$ & Diagnosis \\
\hline 1 & 55 & 3.8 & 0.24 & 69 & 38 & 6 & 30 & DORV, AS, parachute MV \\
\hline 2 & 7 & 3.5 & 0.23 & 108 & 47 & 12 & 35 & HLHS, AS, MS \\
\hline 3 & 4 & 3.7 & 0.25 & 151 & 100 & 35 & 53 & HLHS, AS, MS \\
\hline 4 & 7 & 4 & 0.26 & 105 & 47 & 3 & 44 & HLHS, AS, MS \\
\hline 5 & 16 & 3.5 & 0.24 & 133 & 39 & 34 & 0 & $\begin{array}{l}\text { HLHS, endocardial fibroelastosis } \\
\text { of LV, AS, MS }\end{array}$ \\
\hline 6 & 7 & 4.2 & 0.27 & 122 & 62 & 3 & 60 & HLHS, AS, MS \\
\hline 7 & 12 & 3.5 & 0.23 & 165 & 75 & 13 & 59 & DILV, TGA \\
\hline 8 & 6 & 3.5 & 0.23 & 172 & 82 & 9 & 70 & HLHS, AA, MA \\
\hline 9 & 92 & 4.1 & 0.26 & 105 & 58 & 30 & 17 & DILV, TGA \\
\hline 10 & 16 & 3.9 & 0.25 & 170 & 60 & 1 & 60 & HLHS, AS, MS \\
\hline 11 & 7 & 4 & 0.25 & 167 & 64 & 17 & 44 & HLHS, AS, MS \\
\hline 12 & 6 & 2.9 & 0.2 & 142 & 62 & 1 & 62 & HLHS, AS, MS \\
\hline 13 & 9 & 3.6 & 0.24 & 109 & 50 & 4 & 44 & HLHS, AS, MS \\
\hline
\end{tabular}

$B S A$, Body surface area; $C P B$, cardiopulmonary bypass; $A C C$, aortic crossclamp; $D O R V$, double-outlet right ventricle; $A S$, aortic stenosis; $M V$, mitral valve; $H L H S$, hypoplastic left heart syndrome; $M S$, mitral stenosis; $L V$, left ventricle; DILV, double-inlet left ventricle; TGA, transposition of the great arteries; $A A$, aortic atresia; $M A$, mitral atresia. 
at initiation of CPB. A bolus of aprotinin, 50,000 KIU, was administered, followed by $100,000 \mathrm{KIU}$ per $100 \mathrm{~mL}$ of prime. Our protocol was to administer milrinone $(100 \mu \mathrm{g} / \mathrm{kg})$ before termination of CPB and to initiate dopamine $\left(5 \mu \mathrm{g} \cdot \mathrm{kg}^{-1} \cdot \mathrm{min}^{-1}\right)$ for the immediate time around cessation of bypass. Dopamine was subsequently discontinued if the hemodynamics and ventricular function were satisfactory. Modified ultrafiltration was performed at the completion of CPB in all patients. A pulmonary venous line was inserted into the orifice of the right upper pulmonary vein. A direct oximetric catheter was inserted in the superior vena cava.

\section{Postoperative Management}

Our protocol for management is as follows. The central temperature (esophageal) is maintained between $36^{\circ} \mathrm{C}$ and $37^{\circ} \mathrm{C}$. Postoperative monitoring includes heart rate, end-tidal carbon dioxide, and arterial, superior vena caval, and pulmonary venous pressures. Sedation consists of continuous intravenous infusion of morphine and intermittent injections of a muscle relaxant (pancuronium) and lorezepam. Infants are ventilated with volume control and pressure support. Ventilation volume and rate are adjusted to control $\mathrm{PaCO}_{2}$. Arterial oxygen saturation is maintained between $70 \%$ and $85 \%$. Inotropic agents, vasoactive drugs (milrinone, dopamine, phenoxybenzamine, and vasopressin), and volume infusions (5\% albumin or blood) are administered according to our standard protocol. ${ }^{10}$ Hemoglobin is maintained between 14 and $16 \mathrm{mg} / \mathrm{dL}$.

\section{Methods of Measurements}

$\mathrm{SVO}_{2}, \mathrm{Sa}_{-\mathrm{VO}_{2}}$ and $\mathbf{\Omega}$. Blood samples were taken from arterial, superior vena caval, and pulmonary venous catheters for measurements of oxygen saturation. Arterial blood gas analysis and lactate measurements were obtained. Systemicmixed venous saturation was taken as superior vena caval saturation. $\mathrm{Sa}-\mathrm{VO}_{2}$ was the difference between the arterial and superior vena caval oxygen saturations. $\Omega$ was calculated as $\mathrm{SaO}_{2} / \mathrm{Sa}-\mathrm{VO}_{2}$.

$v_{2} \cdot V_{2}$ was measured continuously with an AMIS2000 mass spectrometer (Innovision A/S, Odense, Denmark). This is a sensitive and accurate method that allows simultaneous measurements of multiple gas fractions. The details are described elsewhere. ${ }^{20}$

Hemodynamics and oxygen transport and arterial lactate. Qp and Qs were calculated by using the direct Fick method. $\mathrm{DO}_{2}$ and the oxygen extraction ratio $\left(\mathrm{ERO}_{2}\right)$ were calculated by using standard equations (Table 2). All values were indexed to body surface area. Arterial lactate levels were measured.

\section{Study Protocol}

This study was performed during the first 72 hours after arrival in the intensive care unit. Values of hemodynamics, oxygen transport, and arterial, superior vena caval, and pulmonary venous saturation were collected at 2-hour intervals during the first 24 hours and at 4-hour intervals from hours 25 through 72 . Sampling was avoided if a change in sedation, paralysis, ventilation, or hemodynamic management was made within 15 minutes.
TABLE 2. Equations using systemic oxygen consumption to calculate hemodynamics and oxygen transport parameters

\begin{tabular}{ll}
\hline Parameters & \multicolumn{1}{c}{ Equations } \\
\hline $\mathrm{Op}\left(\mathrm{L} \cdot \min ^{-1} \cdot \mathrm{m}^{-2}\right)$ & $\mathrm{vo}_{2} /\left(\mathrm{Cpvo}_{2}-\mathrm{CaO}_{2}\right)$ \\
$\mathrm{Os}\left(\mathrm{L} \cdot \mathrm{min}^{-1} \cdot \mathrm{m}^{-2}\right)$ & $\mathrm{vo}_{2} /\left(\mathrm{CaO}_{2}-\mathrm{Cvo}_{2}\right)$ \\
$\mathrm{DO}_{2}\left(\mathrm{~mL} \cdot \mathrm{min}^{-1} \cdot \mathrm{m}^{-2}\right)$ & $\mathrm{Os} \times \mathrm{CaO}_{2}$ \\
$\mathrm{ERO}_{2}$ & $\mathrm{vo}_{2} / \mathrm{Do}_{2}$ \\
\hline
\end{tabular}

$Q p$, pulmonary blood flow; $\mathrm{VO}_{2}$, systemic oxygen consumption; $\mathrm{CpvO}_{2}$, pulmonary venous oxygen content; $\mathrm{CaO}_{2}$, arterial (equals to pulmonary arterial) oxygen content; $\mathrm{Qs}$, systemic blood flow; $\mathrm{CVO}_{2}$, superior vena caval oxygen content; $\mathrm{Do}_{2}$, systemic oxygen delivery; $\mathrm{ERO}_{2}$, oxygen extraction ratio.

\section{Data Analysis}

Data are expressed as means \pm standard deviation. The generalized linear model for repeated measures was used to determine the nature of any time trend of the measures over the 72-hour study period. Where appropriate for given measures, logarithmic and polynomial transformations were tested for the best fit over time. Correlations between the indirect indicators $\mathrm{SvO}_{2}, \mathrm{Sa} \mathrm{VO}_{2}$, and $\Omega$ and the direct measures of hemodynamics and oxygen transport were sought by using the generalized linear model for repeated measures without regard to time. Logarithmic transformations of both variables being compared was used when necessary to model nonlinear relationships. All data analysis was performed with SAS statistical software version 8 (SAS Institute, Inc, Cary, NC).

\section{Results}

\section{Patients}

During the study period, 16 patients underwent the Norwood procedure. There was no incidence of circulatory collapse or death during the study period. All patients survived to hospital discharge. Extubation occurred between 2 and 16 days (median, 7 days) after the procedure, except in one child who had vocal cord complications. Extubation for that infant occurred at 90 days and after the stage 2 procedure. The neonate extubated on day 2 had the study terminated at that time. One child had sudden hemodynamic collapse subsequent to the study and required resuscitation with extracorporeal membrane oxygenation. That child survived and was discharged home after the stage 2 procedure.

\section{Changes of $\mathrm{SvO}_{2}, \mathrm{Sa} \mathrm{vo}_{2}$, and $\boldsymbol{\Omega}$ Over Time}

Figure 1 shows the profiles of $\mathrm{SvO}_{2}, \mathrm{Sa}_{-} \mathrm{VO}_{2}, \Omega$, hemodynamics, and oxygen transport in 13 patients during the first 72 hours after arrival in the intensive care unit after the Norwood procedure. All measures showed broad interindividual variations.

Analogous trends over time, although in different directions, were seen with $\mathrm{SvO}_{2}, \mathrm{Sa}-\mathrm{VO}_{2}$, and $\Omega$. There were wide fluctuations within individuals. $\mathrm{SvO}_{2}$ and $\Omega$ showed an initial rapid increase in the first 12 hours, a subsequent slow increase peaking around 28 to 32 hours, and thereafter a slow decrease in a complex polynomial function $(P<$ 

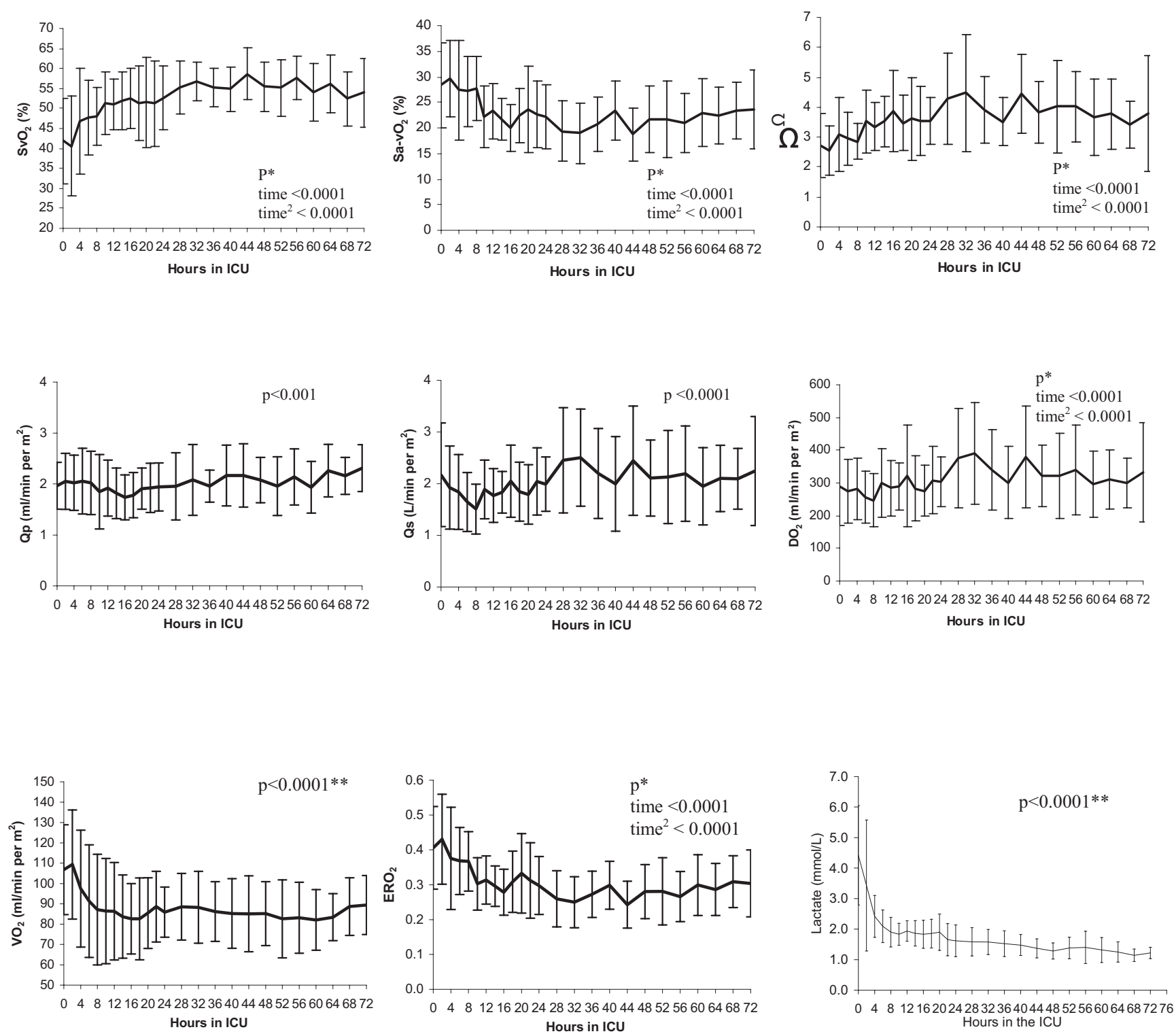

Figure 1. Mean \pm standard deviation values of superior vena caval oxygen saturation $\left(\mathrm{Svo}_{2}\right)$, the difference between arterial and superior vena caval oxygen saturations $\left(\mathrm{Sa}^{\mathrm{v}} \mathrm{vo}_{2}\right)$, oxygen excess factor $\left(\boldsymbol{\Omega}=\mathrm{SaO}_{2} / \mathrm{Sa} \mathrm{vo}_{2}\right)$, and the direct measures of hemodynamics and oxygen transport, including pulmonary (Qp) and systemic ( $Q s)$ blood flows, systemic oxygen delivery $\left(\mathrm{Do}_{2}\right)$, systemic oxygen consumption $\left(\mathrm{vO}_{2}\right)$, oxygen extraction ratio $\left(E \mathrm{ER}_{2}\right)$, and arterial lactate level in 13 patients during the first $\mathbf{7 2}$ hours after arrival in the intensive care unit (ICU) after the Norwood procedure. The slope of change is highest for $\mathrm{Svo}_{2}, \mathrm{Sa}^{-} \mathrm{vo}_{2}$, and $\Omega$ in the first 12 hours of recovery. The change is explained by changes in $\mathrm{vo}_{2}$ during the same time frame. There are parallel or mirror-imaged changes with respect to $\mathrm{ERO}_{2}$. ${ }^{*}$ Data were entered after polynomial transformation, with time indicating the early trend, and time $^{2}$ indicating the later trend. ${ }^{*}$ After logarithmic transformation.

.0001). Sa- $-\mathrm{VO}_{2}$ showed the same trend but as a mirror image, with a rapid initial decrease in the first 12 hours and a slow decrease until 28 to 32 hours. Thereafter, there was a slow increase $(P<.0001)$.
Changes of Direct Measures of Hemodynamics and Oxygen Transport

Changes of direct measures of hemodynamics and oxygen transport were highly variable, on an individual basis, as 

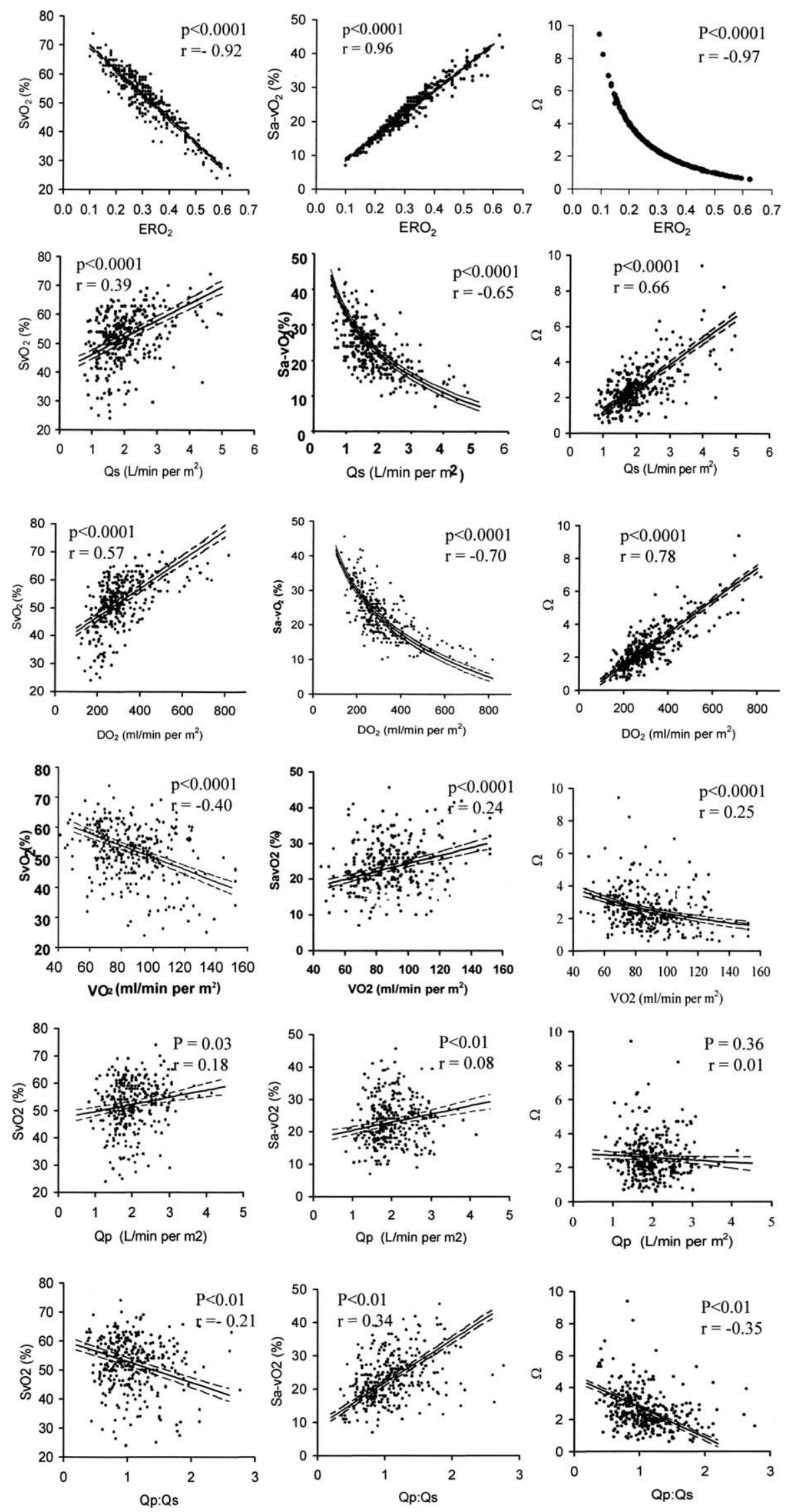

Figure 2. The correlations between superior vena caval oxygen saturation $\left(\mathrm{SvO}_{2}\right)$, the difference between arterial and superior vena caval oxygen saturations $\left(\mathrm{Sa}-\mathrm{Vo}_{2}\right)$, and oxygen excess factor $(\Omega=$ $\mathrm{SaO}_{2} / \mathrm{SavO}_{2}$ ) and oxygen extraction ratio $\left(E \mathrm{Ro}_{2}\right)$, systemic blood flow (Qs), oxygen delivery $\left(\mathrm{Do}_{2}\right)$, oxygen consumption $\left(\mathrm{Vo}_{2}\right)$, pulmonary blood flow (Op), and $0 p / 0$ s in 13 patients during the first 72 hours after arrival in the intensive care unit (ICU) after the Norwood procedure. 
demonstrated by the broad standard deviations. Qp and Qs showed a small but significant linear increase over time $(P<.001$ for $\mathrm{Qp}, P<.0001$ for $\mathrm{Qs})$. Qs was significantly lower during the first 12 hours compared with the following 60 hours $(P<.001)$. The same analysis for Qp was not significant $(P=.62) . \mathrm{Do}_{2}$ showed a significant change over time $(P<.0001)$, with a slow increase peaking around 28 to 32 hours, followed by a slow decrease. $\mathrm{Do}_{2}$ was significantly lower during the first 12 hours compared with the following 60 hours $(P<.001) . \mathrm{vO}_{2}$ was related to time after logarithmic transformation $(P<.0001)$. There was a significant decrease in the first 12 hours, as there was with arterial lactate levels $(P<.0001) . \mathrm{ERo}_{2}$ was related to time after logarithmic transformation, with a rapid decrease in the first 12 hours $(P<.0001)$. Central temperature was relatively stable $\left(36.6^{\circ} \mathrm{C} \pm 0.5^{\circ} \mathrm{C}\right)$, with a small linear increase over time $(P=.0002)$.

\section{Correlations Among $\mathrm{Svo}_{2}, \mathrm{Sa}^{-v_{2}}, \mathbf{\Omega}$ and Direct} Measures of Hemodynamics and Oxygen Transport

Figure 2 and Table 3 show the generalized linear model correlation among $\mathrm{SvO}_{2}, \mathrm{Sa}_{-} \mathrm{vO}_{2}$, and $\Omega$ and the direct measures of hemodynamics and oxygen transport. For significant correlations $(P<.05)$, we have classified an $r$ value of less than 0.30 to be a poor correlation, an $r$ value of 0.31 to 0.70 to be a variable or moderate correlation, and an $r$ value of greater than 0.70 to be a close correlation.

Over the entire study period, there was a close correlation of $\mathrm{SvO}_{2}, \mathrm{Sa}_{-} \mathrm{vO}_{2}$, and $\Omega$ with $\mathrm{ERo}_{2}(r=0.92,0.96$, and 0.97 , respectively; $P<.0001$ for all). $\mathrm{SvO}_{2}, \mathrm{Sa}_{-} \mathrm{vO}_{2}$, and $\Omega$ were variably correlated with Qs $(r=0.39,-0.65$, and 0.66 , respectively; $P<.0001$ for all) and variably or closely correlated with $\mathrm{Do}_{2}(r=0.57,-0.70$, and 0.78 , respectively; $P<.0001$ for all). $\mathrm{SvO}_{2}, \mathrm{Sa}_{-} \mathrm{vO}_{2}$, and $\Omega$ were significantly but poorly to moderately correlated with $\mathrm{Qp} / \mathrm{Qs}(r$ $=0.21,0.34$, and 0.35, respectively; $P<.0001$ for all). Inclusion of $\mathrm{Qp}$ and $\mathrm{Qs}$ as separate variables in the $\mathrm{Qp} / \mathrm{Qs}$ correlation demonstrated no correlation $(P>.05$ for all). $\mathrm{SvO}_{2}, \mathrm{Sa}_{-} \mathrm{VO}_{2}$, and $\Omega$ were poorly and variably correlated with $\mathrm{vO}_{2}(r=0.40,0.24$, and 0.25 , respectively; $P<.0001$ for all). Inclusion of $\mathrm{VO}_{2}$ to the $\mathrm{Qs}$ and $\mathrm{Do}_{2}$ analysis significantly improved the correlations with $\mathrm{SvO}_{2}$ (increased $r$ from 0.39 to 0.66 for Qs and increased $r$ from 0.57 to 0.84 for $\mathrm{Do}_{2}$ ), $\mathrm{Sa}^{-\mathrm{VO}_{2}}$ (increased $r$ from -0.65 to -0.86 for $\mathrm{Qs}$ and from -0.70 to -0.88 for $\mathrm{Do}_{2}$ ), and $\Omega$ (increased $r$ from 0.66 to 0.87 for Qs and from 0.78 to 0.97 for $\mathrm{Do}_{2}$ ). All $P$ values for the inclusion of $\mathrm{vo}_{2}$ were less than $.0001 . \mathrm{SvO}_{2}$ and $\mathrm{Sa}-\mathrm{VO}_{2}$ were poorly correlated with $\mathrm{Qp}(r=0.18, P=$ .03 and $r=0.08, P<.01$, respectively), and $\Omega$ showed no correlation with $\mathrm{Qp}(r=0.01, P=.36)$.

\section{Discussion}

After the introduction of the Norwood procedure, the strategy for postoperative management was primarily directed at
TABLE 3. Statistical analysis results using the generalized linear model for repeated measures of the correlations between $\mathrm{Sv02}, \mathrm{Sa}^{-\mathrm{vo}_{2}}$, and $\Omega$ and the direct measures of hemodynamics and oxygen transport in 13 patients during the 72 hours after the Norwood procedure

\begin{tabular}{|c|c|c|c|c|c|}
\hline $\begin{array}{l}\text { Independent } \\
\text { variables }\end{array}$ & $\begin{array}{l}\text { Dependent } \\
\text { variable }\end{array}$ & Intercept & Coefficient & $r$ & $P$ value \\
\hline \multirow[t]{3}{*}{$\mathrm{ERo}_{2}$} & $\mathrm{SvO}_{2}$ & 78.1530 & -84.0414 & -0.92 & $<.0001$ \\
\hline & $\mathrm{Sa}-\mathrm{VO}_{2}$ & 2.2918 & 67.2630 & 0.96 & $<.0001$ \\
\hline & $\Omega^{*}$ & -2.0088 & -3.7520 & -0.97 & $<.0001$ \\
\hline \multirow[t]{3}{*}{ Os } & $\mathrm{SvO}_{2}{ }^{*}$ & 43.2140 & 13.9958 & 0.39 & $<.0001$ \\
\hline & Sa- $-\mathrm{VO}_{2}{ }^{*}$ & 33.4813 & -16.2394 & -0.65 & $<.0001$ \\
\hline & $\Omega$ & -0.1597 & 1.3541 & 0.66 & $<.0001$ \\
\hline \multirow[t]{3}{*}{$\mathrm{Do}_{2}$} & $\mathrm{SvO}_{2}{ }^{*}$ & -61.2285 & 19.9879 & 0.57 & $<.0001$ \\
\hline & Sa- $\mathrm{VO}_{2}{ }^{*}$ & 123.44 & -17.6873 & -0.70 & $<.0001$ \\
\hline & $\Omega$ & -16.2926 & 3.3264 & 0.78 & $<.0001$ \\
\hline \multirow[t]{3}{*}{$\mathrm{VO}_{2}$} & $\mathrm{SvO}_{2}$ & 69.2978 & -0.1949 & -0.40 & $<.0001$ \\
\hline & Sa- $\mathrm{VO}_{2}$ & 13.5039 & 0.1091 & 0.24 & $<.0001$ \\
\hline & $\Omega^{*}$ & 9.9743 & -1.6618 & -0.25 & $<.0001$ \\
\hline \multirow[t]{3}{*}{ Op } & $\mathrm{SvO}_{2}$ & 46.0825 & 3.0292 & 0.18 & .03 \\
\hline & $\mathrm{Sa}-\mathrm{VO}_{2}$ & 18.5011 & 2.2865 & 0.08 & $<.01$ \\
\hline & $\Omega$ & 2.7847 & -0.1027 & -0.01 & .36 \\
\hline \multirow[t]{3}{*}{ Qp/Os } & $\mathrm{SvO}_{2}$ & 60.2282 & -7.3649 & -0.21 & $<.0001$ \\
\hline & $\mathrm{Sa}-\mathrm{VO}_{2}$ & 8.8763 & 12.9871 & 0.34 & $<.0001$ \\
\hline & $\Omega$ & 4.6510 & -1.8934 & -0.35 & $<.0001$ \\
\hline
\end{tabular}

$\mathrm{SVO}_{2}$, superior vena caval oxygen saturation; $\mathrm{Sa}_{\mathrm{V}} \mathrm{VO}_{2}$, difference between arterial and superior vena caval oxygen saturations; $\Omega$, oxygen excess factor; $E \mathrm{RO}_{2}$, oxygen extraction ratio; $Q \mathrm{~s}$, systemic blood flow; $\mathrm{Do}_{2}$, systemic oxygen delivery; $\mathrm{V}_{2}$, systemic oxygen consumption; $Q p$, pulmonary blood flow. *Data were entered after logarithmic transformation.

balancing Qp/Qs through manipulation of pulmonary vascular resistance. More recent strategy has focused on the importance of Qs and systemic vascular resistance. ${ }^{9-12}$ As such, measures thought to reflect systemic cardiac output have become increasingly used. Low $\mathrm{SvO}_{2}$ has been shown to correlate with a base deficit. ${ }^{5} \mathrm{Sa}-\mathrm{VO}_{2}$ reflects the adequacy of $\mathrm{Do}_{2},{ }^{4,11,12}$ and $\Omega$ is a ratio of available oxygen to extracted oxygen $\left(\mathrm{SaO}_{2} / \mathrm{Sa}^{-} \mathrm{VO}_{2}\right)$. Each of these is thought to be a surrogate measure reflecting $\mathrm{Do}_{2}$. Present management strategies have focused on maintaining physiologic conditions whereby these surrogate measures have appropriate values. By using respiratory mass spectrometry to measure $\mathrm{vo}_{2}$, we now have the ability to directly calculate $\mathrm{Do}_{2}, \mathrm{Qp}$, and Qs using the Fick equation and to test the validity of the surrogate measures using correlations to the measured and calculated parameters.

\section{Correlation of Surrogate Measures and $\mathrm{ERo}_{2}$}

There was a significant and close correlation of $\mathrm{ERO}_{2}$ to $\mathrm{SvO}_{2}, \mathrm{Sa}_{-\mathrm{VO}_{2}}$, and $\Omega(r=0.92,0.96$, and 0.97 , respectively). $\mathrm{ERO}_{2}$ is an oxygen transport measure that provides a ratio that incorporates the 3 major components of oxygen transport: oxygen content, $\mathrm{Do}_{2}$, and $\mathrm{vo}_{2}$. This study demonstrates 


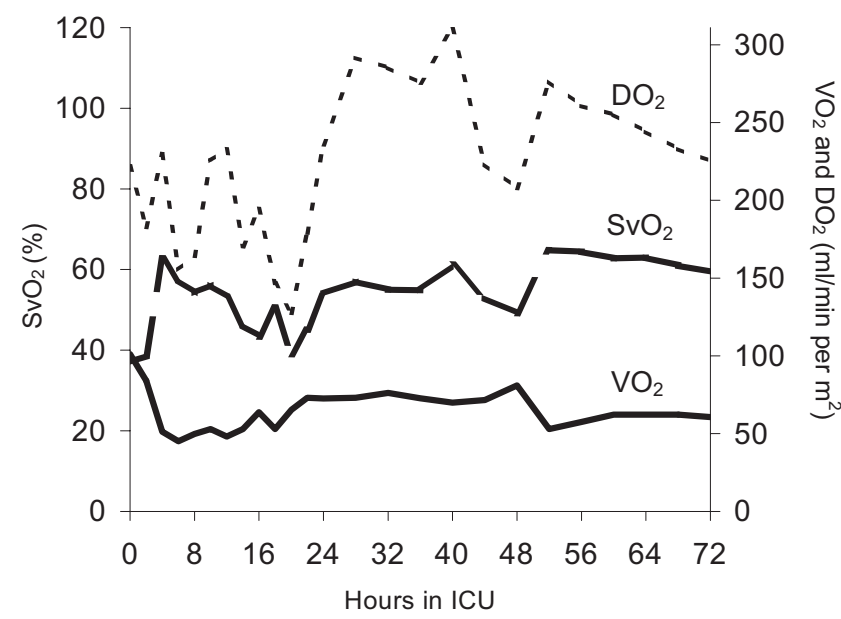

Figure 3. An example of increasing superior vena caval oxygen saturation $\left(\mathrm{SvO}_{2}\right)$ in the presence of a decreasing systemic oxygen delivery $\left(\mathrm{Do}_{2}\right)$. In this patient the finding in the first $\mathbf{1 2}$ hours after arrival in the intensive care unit (ICU) can be explained by the disproportionate decrease in systemic oxygen consumption $\left(\mathrm{VO}_{2}\right)$. Because $\mathrm{Sv}_{2}$ is a single measure of the balance of $\mathrm{Do}_{2}$ and $\mathrm{vo}_{2}$, the source of a changing $\mathrm{SvO}_{2}$ might be $\mathrm{Do}_{2}, \mathrm{vo}_{2}$, or both.

that each of the surrogate measures used is most accurately a reflector of $\mathrm{ERO}_{2}$. The very close reciprocal correlation curve seen with $\Omega\left(\mathrm{SaO}_{2} / \mathrm{Sa}_{-} \mathrm{VO}_{2}\right)$ is explained by the fact that it is intrinsically the ratio of $\mathrm{Do}_{2}$ to $\mathrm{VO}_{2}$ and thus the reciprocal of $\mathrm{ERO}_{2}$.

However, $\mathrm{ERO}_{2}$ might not fully account for the adequacy of $\mathrm{Do}_{2}$ because of the potential for changes induced by the phenomenon of $\mathrm{DO}_{2}$-dependent oxygen extraction. Paradoxically, in the presence of poor or worsening $\mathrm{Do}_{2}$, a disproportionate decrease in $\mathrm{VO}_{2}$ might yield an adequate or improving $\mathrm{SvO}_{2}$ (a close surrogate for $\mathrm{ERO}_{2}$ ), as shown in a specific example of a patient (Figure 3 ) who had a normalizing lactate level and normal base deficit despite a decreasing $\mathrm{Do}_{2}$.

\section{Correlation of Surrogate Measures to Qs and $\mathrm{Do}_{2}$}

Correlation of $\mathrm{SvO}_{2}, \mathrm{Sa}_{-} \mathrm{vo}_{2}$, and $\Omega$ to Qs was significant but variable. There was correlation to a moderate degree ( $r=0.39,0.65$, and 0.66 , respectively). Correlation to $\mathrm{Do}_{2}$ is moderate to close for the same 3 variables $(r=0.57,0.70$, and 0.78 , respectively). The variability and failure to achieve a uniformly close correlation can be explained by the fact that each of the surrogate measures is a single measure or ratio that is dependent on changes in oxygen content, $\mathrm{DO}_{2}$, and $\mathrm{VO}_{2}$ (ie, all the components of oxygen transport). As seen in Figure 2, Qs and $\mathrm{Do}_{2}$ are marginal in the first 24 hours and subsequently gradually increase, a profile that has been seen in other studies after CPB. ${ }^{21,26,27}$ The improvements in $\mathrm{SvO}_{2}, \mathrm{Sa}_{-} \mathrm{VO}_{2}$, and $\Omega$ in the first 12 to
24 hours occurred during the period when $\mathrm{Qs}$ and $\mathrm{Do}_{2}$ were most decreased. This finding is explained by the improvement in $\mathrm{VO}_{2}$, as discussed below. In previous analysis, based on an estimated and fixed $\mathrm{vO}_{2}$, the improvement was attributed to favorable changes in $\mathrm{Qs}$ and $\mathrm{Do}_{2} \cdot{ }^{3,4,19}$

\section{Correlation of Surrogate Measures to $\mathrm{vo}_{2}$}

There was significant but moderate-to-poor correlation of $\mathrm{VO}_{2}$ to $\mathrm{SvO}_{2}, \mathrm{Sa}_{\mathrm{VO}}$, and $\Omega(r=0.40,0.24$, and 0.25, respectively). The most rapid improvement in all the indirect indicators was seen in the first 12 hours after the Norwood procedure and can be explained by the slope of the decrease in $\mathrm{VO}_{2}$ during the first 12 hours. The $\mathrm{VO}_{2}$ profile is similar to previously reported findings for other cardiac procedures. ${ }^{21}$ The addition of $\mathrm{VO}_{2}$ to the regression analysis increases the correlation of all 3 variables, $\mathrm{SvO}_{2}, \mathrm{Sa}_{\mathrm{VO}}$, and $\Omega$, to $r$ values of 0.66 to 0.92 , all of which are significant. Qs and $\mathrm{Do}_{2}$ are contributors to the changes in $\mathrm{SvO}_{2}, \mathrm{Sa}_{\mathrm{VO}}$, and $\Omega$, particularly over the later time frame, when there are less changes in $\mathrm{VO}_{2}$.

Present strategy to treat postoperative Norwood patients has been to compartmentalize Qp (a contributor to oxygen content) and Qs (the major contributor to $\mathrm{Do}_{2}$ ). Because there have been little clinical data on $\mathrm{VO}_{2}$, manipulation of $\mathrm{VO}_{2}$ has not gone beyond theoretic concerns. Major contributors to $\mathrm{VO}_{2}$ are temperature, ${ }^{20}$ inflammatory mediators, ${ }^{21,24}$ and inotropic agents. ${ }^{28}$ The addition of $\mathrm{vO}_{2}$ as a third compartment for a targeted treatment strategy, particularly in the first 12 hours, when there is a significant increase, remains to be explored both for the ability to manipulate $\mathrm{VO}_{2}$ and for its effect on hemodynamic stability.

\section{Correlation of Surrogate Measures and Qp}

There was little correlation of Qp to $\mathrm{SvO}_{2}$ and $\mathrm{Sa}_{-} \mathrm{VO}_{2}(r=$ 0.18 and 0.08 , respectively) and no correlation to $\Omega(r=$ 0.01). These findings suggest that Qp estimates require standard measurement of Qp/Qs or Fick equation calculations. Surrogate measures of $\mathrm{Do}_{2}$ might reflect the adequacy of oxygenation for the ranges of systemic arterial saturation seen in this study ( $55 \%$ to $86 \%$ ).

\section{Limitations}

$\mathrm{SvO}_{2}$ was used as an estimate of the mixed venous saturation for the calculations of $\mathrm{Qs}$ and $\mathrm{Do}_{2}$. This measure does not account for potential differences in the inferior vena caval saturation. ${ }^{29,30}$ Further investigations analyzing both superior and inferior vena caval oxygen saturation are warranted.

\section{Conclusions}

Clinical measures of adequate systemic $\mathrm{Do}_{2}, \mathrm{SvO}_{2}, \mathrm{Sa} \mathrm{VO}_{2}$, and $\Omega$ do not completely reflect the changes in $\mathrm{Qs}$ and $\mathrm{Do}_{2}$ because of the variability of $\mathrm{vo}_{2} . \mathrm{SvO}_{2}, \mathrm{Sa}-\mathrm{vO}_{2}$, and $\Omega$ are 
measures of both $\mathrm{Do}_{2}$ and $\mathrm{vO}_{2}$, as demonstrated by their close correlation to $\mathrm{ERo}_{2}$. Measured oxygen transport and hemodynamics might improve the optimization of a postoperative management strategy for individual patients.

\section{References}

1. Ashburn DA, McCrindle BW, Tchervenkov CI, Jacobs ML, Lofland GK, Bove EL, et al. Outcomes after the Norwood operation in neonates with critical aortic stenosis or aortic valve atresia. $J$ Thorac Cardiovasc Surg. 2003;125:1070-82.

2. Mahle WT, Spray TL, Wernovsky G, Gaynor JW, Clark BJ III. Survival after reconstructive surgery for hypoplastic left heart syndrome: a 15-year experience from a single institution. Circulation. 2000;102(suppl 3):III136-41.

3. Charpie JR, Dekeon MK, Goldberg CS, Mosca RS, Bove EL, Kulik TJ. Postoperative hemodynamics after Norwood palliation for hypoplastic left heart syndrome. Am J Cardiol. 2001;87:198-202.

4. Tweddell JS, Hoffman GM, Fedderly RT, Ghanayem NS, Kampine JM, Berger S, et al. Patients at risk for low systemic oxygen delivery after the Norwood procedure. Ann Thorac Surg. 2000;69:1893-9.

5. Hoffman GM, Ghanayem NS, Kampine JM, Berger S, Mussatto KA, Litwin SB, et al. Venous saturation and the anaerobic threshold in neonates after the Norwood procedure for hypoplastic left heart syndrome. Ann Thorac Surg. 2000;70:1515-20.

6. Bradley SM, Simsic JM, Atz AM. Hemodynamic effects of inspired carbon dioxide after the Norwood procedure. Ann Thorac Surg. 2001; 72:2088-93.

7. Bradley SM, Atz AM, Simsic JM. Redefining the impact of oxygen and hyperventilation after the Norwood procedure. $J$ Thorac Cardiovasc Surg. 2004;127:473-80.

8. Taeed R, Schwartz SM, Pearl JM, Raake JL, Beekman RH III, Manning PB, et al. Unrecognized pulmonary venous desaturation early after Norwood palliation confounds Gp:Gs assessment and compromises oxygen delivery. Circulation. 2001;103:2699-704.

9. De Oliveira NC, Ashburn DA, Khalid F, Burkhart HM, Adatia IT, Holtby HM, et al. Prevention of early sudden circulatory collapse after the Norwood operation. Circulation. 2004;110(suppl 1):II133-8.

10. De Oliveira NC, Van Arsdell GS. Practical use of alpha blockade strategy in the management of hypoplastic left heart syndrome following stage one palliation with a Blalock-Taussig shunt. Semin Thorac Cardiovasc Surg Pediatr Card Surg Annu. 2004;7:11-5.

11. Tweddell JS, Hoffman GM, Fedderly RT, Berger S, Thomas JP Jr, Ghanayem NS, et al. Phenoxybenzamine improves systemic oxygen delivery after the Norwood procedure. Ann Thorac Surg. 1999;67: 161-7.

12. Hoffman GM, Tweddell JS, Ghanayem NS, Mussatto KA, Stuth EA, Jaquis RD, et al. Alteration of the critical arteriovenous oxygen saturation relationship by sustained afterload reduction after the Norwood procedure. J Thorac Cardiovasc Surg. 2004;127:738-45.

13. Kitaichi T, Chikugo F, Kawahito T, Hori T, Masuda Y, Kitagawa T. Suitable shunt size for regulation of pulmonary blood flow in a canine model of univentricular parallel circulations. J Thorac Cardiovasc Surg. 2003;125:71-8.

14. Riordan CJ, Randsbeck F, Storey JH, Montgomery WD, Santamore WP, Austin EH III. Effects of oxygen, positive end-expiratory pressure, and carbon dioxide on oxygen delivery in an animal model of the univentricular heart. J Thorac Cardiovasc Surg. 1996;112:644-54.

15. Barnea O, Austin EH, Richman B, Santamore WP. Balancing the circulation: theoretic optimization of pulmonary/systemic flow ratio in hypoplastic left heart syndrome. J Am Coll Cardiol. 1994;24:1376-81.

16. Barnea O, Santamore WP, Rossi A, Salloum E, Chien S, Austin EH, et al. Estimation of oxygen delivery in newborns with a univentricular circulation. Circulation. 1998;98:1407-13.

17. Migliavacca F, Pennati G, Dubini G, Fumero R, Pietrabissa R, Urcelay G, et al. Modeling of the Norwood circulation: effects of shunt size, vascular resistances, and heart rate. Am J Physiol Heart Circ Physiol. 2001;280:H2076-86.

18. Maher KO, Pizarro C, Gidding SS, Januszewska K, Malec E, Norwood WI Jr, et al. Hemodynamic profile after the Norwood procedure with right ventricle to pulmonary artery conduit. Circulation. 2003;108:782-4

19. Rossi AF, Sommer RJ, Lotvin A, Gross RP, Steinberg LG, Kipel G, et al. Usefulness of intermittent monitoring of mixed venous oxygen saturation after stage I palliation for hypoplastic left heart syndrome. Am J Cardiol. 1994;73:1118-23.

20. Li J, Schulze-Neick I, Lincoln C, Shore D, Scallan M, Bush A, et al. Oxygen consumption after cardiopulmonary bypass surgery in children: determinants and implications. J Thorac Cardiovasc Surg. 2000; 119:525-33.

21. Li J, Hoschtitzky A, Allen ML, Elliott MJ, Redington AN. Improved balance between oxygen consumption and oxygen delivery in euthermic infants after cardiopulmonary bypass with modified ultrafiltration. Ann Thorac Surg. 2004;78:1389-96.

22. Li J, Hoskote A, Hickey C, VanArsdell G, Redington A, Adatia I. Hypercapnia improves systemic oxygenation and decreases oxygen consumption and blood lactate levels in children after bidirectional cavopulmonary shunt operation. Crit Care Med. 2005;33:984-9.

23. Li J, Bush A, Schulze-Neick I, Penny DJ, Redington AN, Shekerdemian LS. Measured versus estimated oxygen consumption in ventilated patients with congenital heart disease: the validity of predictive equations. Crit Care Med. 2003;31:1235-40.

24. Oudemans-van Straaten HM, Jansen PG, te VH, Beenakkers IC, Stoutenbeek CP, van Deventer SJ, et al. Increased oxygen consumption after cardiac surgery is associated with the inflammatory response to endotoxemia. Intensive Care Med. 1996;22:294-300.

25. Azakie T, Merklinger SL, McCrindle BW, Van Arsdell GS, Lee KJ, Benson LN, et al. Evolving strategies and improving outcomes of the modified Norwood procedure: a 10-year single-institution experience. Ann Thorac Surg. 2001;72:1349-53.

26. Wernovsky G, Wypij D, Jonas RA, Mayer JE Jr, Hanley FL, Hickey $\mathrm{PR}$, et al. Postoperative course and hemodynamic profile after the arterial switch operation in neonates and infants. A comparison of low-flow cardiopulmonary bypass and circulatory arrest. Circulation. 1995;92:2226-35.

27. Gessler P, Pfenninger J, Pfammatter JP, Carrel T, Baenziger O, Dahinden C. Plasma levels of interleukin-8 and expression of interleukin- 8 receptors on circulating neutrophils and monocytes after cardiopulmonary bypass in children. J Thorac Cardiovasc Surg. 2003;126:718-25.

28. Penny DJ, Sano T, Smolich JJ. Increased systemic oxygen consumption offsets improved oxygen delivery during dobutamine infusion in newborn lambs. Intensive Care Med. 2001;27:1518-25.

29. Kety SS, Schmidt CF. The effects of altered arterial tensions of carbon dioxide and oxygen on cerebral blood flow and cerebral oxygen consumption of normal young man. J Clin Invest. 1948;27:484-92.

30. Landow L, Phillips DA, Heard SO, Prevost D, Vandersalm TJ, Fink MP. Gastric tonometry and venous oximetry in cardiac surgery patients. Crit Care Med. 1991;19:1226-33.

\section{Discussion}

Dr Scott M. Bradley (Charleston, SC). This study is important because it is the first to measure $\mathrm{VO}_{2}$ in postoperative Norwood patients. The findings confirm one of our management beliefs but challenge another.

One of our beliefs is that a mixed venous oxygen saturation that is higher and an arteriovenous oxygen saturation difference that is lower are desirable. This is because they correlate with higher Qs and $\mathrm{DO}_{2}$. Your study confirms this belief. Although some of the correlations were rated as moderate, the directly measured values of $\mathrm{VO}_{2}$ actually improved the correlation. These findings therefore affirm postoperative management aimed at maximizing mixed venous oxygen saturation.

In contrast, this report challenges our understanding of the physiology of the first 48 hours. Immediately after surgical intervention, mixed venous saturation is low, and arteriovenous saturation difference is high. They then improve over the next 48 hours. As you noted, this has been observed in previous studies 
and interpreted to indicate low systemic cardiac output. However, your study shows that low cardiac output plays only a minor role. The major reason that mixed venous saturation is low is that $\mathrm{VO}_{2}$ is high immediately after surgical intervention and then decreases markedly over the next 48 hours. Like many interesting findings, this one is somewhat counterintuitive because this is exactly the time $\mathrm{VO}_{2}$ might be expected to be low because many of the patients are sedated, paralyzed, and mechanically ventilated at this time.

The first question then is this: Why is $\mathrm{VO}_{2}$ high early after surgical intervention? Is it a generalized inflammatory response to bypass, or is it due to the particular CPB technique used in these patients? Your article indicates that your patients underwent $\mathrm{CPB}$ with phenoxybenzamine with low-flow rather than high-flow bypass, as recommended by Roger Mee. Does this create a wholebody oxygen debt in the operating room that must then be repaid in the intensive care unit? Could you give us your group's thoughts on the explanation for this very interesting finding.

Dr Li. Thank you for your comments. It is well documented that $\mathrm{VO}_{2}$ increases after $\mathrm{CPB}$. The increase in $\mathrm{vO}_{2}$ has been attributed to several factors, including rewarming from hypothermic $\mathrm{CPB}$, repayment of oxygen debt, and, most importantly, systemic inflammatory response. As shown in our previous study in a group of older children after complete repair of congenital heart disease, the initial postoperative $\mathrm{VO}_{2}$ was also high, and similarly to our current study, it decreased significantly over the first 12 hours. The decrease in $\mathrm{VO}_{2}$ coincided with the decrease in circulating cytokine levels.

Dr Bradley. Is there any relationship, for example, between the level of $\mathrm{VO}_{2}$ coming out of the operating room and the length of $\mathrm{CPB}$ ?

Dr Li. In this particular group of patients, the longer CPB time was associated with a higher $\mathrm{vO}_{2}$.

Dr Bradley. The second question is this: Can this phenomenon be avoided? Specifically, were anti-inflammatory strategies, such as modified ultrafiltration, preoperative steroids, or aprotinin, used in your patients? Alternatively, should we be keeping our patients deliberately cool for the first 48 hours after surgical intervention? That might be an unfair question to ask you.

Dr Li. I will try.

Dr Bradley. Do you know whether your patients had modified ultrafiltration?

Dr Li. Yes, they all had modified ultrafiltration. Modified ultrafiltration has been reported to filter out some cytokines. Again, in our previous study in the older group of children with the use of modified ultrafiltration, the postoperative cytokine levels were generally lower compared with data in the literature in children without the use of modified ultrafiltration. This might reduce the systemic inflammatory response, potentially resulting in a decrease in $\mathrm{VO}_{2}$.

All children received at least intraoperative steroids. Steroids have been reported to reduce the systemic inflammatory response and thus might reduce $\mathrm{VO}_{2}$. In fact, we are proposing a research project to investigate the effect of steroids on $\mathrm{VO}_{2}$ in children during and after CPB. All children received aprotinin. The central body temperature was maintained at euthermia for the first 48 hours. In our previous studies we have demonstrated that the increase in $\mathrm{VO}_{2}$ during the early post-CPB period is mainly attributed to the increase in central body temperature: for a $1^{\circ} \mathrm{C}$ increase in central body temperature, $\mathrm{VO}_{2}$ increases by $11 \%$, and simply maintaining body temperature at euthermia results in a continuous decrease in $\mathrm{VO}_{2}$.

Indeed, manipulating $\mathrm{VO}_{2}$ is increasingly realized to be an important alternative component to optimize the balance of oxygen transport in children with limited reserve of cardiac function early after CPB.

Dr Bradley. Perioperative steroids or aprotinin use?

Dr Li. Yes, we all used steroids. I think it might contribute, too. It might indeed reduce $\mathrm{VO}_{2}$. In fact, we are thinking of proposing a study to compare-to investigate this effect on $\mathrm{VO}_{2}$.

Dr Bradley. Thank you. I think it is a very interesting and important study.

Dr Antonio Corno (Liverpool, United Kingdom). Surgeons are generally very simple-minded. Do you have a practical suggestion for the surgeon in the postoperative care of this patient? If we want to improve the oxygen saturation, that means the balance between $\mathrm{Do}_{2}$ and $\mathrm{VO}_{2}$. What we can do as surgeons is to provide a higher total Qp. Should we modify our surgical technique to increase the total Qp knowing that this will cause an increase of the total $\mathrm{vO}_{2}$ because of increased myocardial consumption? How can you maintain a positive balance to provide a better $\mathrm{Do}_{2}$ ?

Dr Li. In this group of patients, we have also analyzed the relationships between pulmonary vascular resistance, systemic vascular resistance, and $\mathrm{Do}_{2}$. Our data showed that varying $\mathrm{Qp}$ had little contribution to systemic $\mathrm{Do}_{2}$, largely because of the mechanical limitation from the Blalock-Taussig shunt. The best way to improve systemic $\mathrm{Do}_{2}$ is to maintain a relatively low and stable systemic vascular resistance and, additionally, to maintain a relatively high level of hemoglobin.

Dr Carl L. Backer (Chicago, Ill). Was there any difference in the management strategy as far as the ventilator that you use in the operating room compared with the one that you use in the intensive care unit?

One of the problems we have with our patients is that we have a completely different ventilator system in the operating room than we have in the intensive care unit. There is always a transition phase after transport, with hand ventilation to the intensive care unit ventilator, and I just wondered whether you thought that played any role in the $\mathrm{VO}_{2}$ in the immediate time period when the patient arrives in the intensive care unit?

Dr Li. The ventilator systems are different in the operating room and intensive care unit, but our ventilation management protocols are the same for these patients in the 2 settings. Yes, there is a transition phase after transport, with hand ventilation to the intensive care unit ventilator, and certain adjustment of ventilation was often required to achieve adequate levels of arterial carbon dioxide and oxygen because they might have profound effects on both $\mathrm{Do}_{2}$ and $\mathrm{vO}_{2}$. Yet we have found the hemodynamic variability to ventilation issues to be minimized by aggressive afterload reduction with phenoxybenzamine. 